\title{
A STUDY ON EXTRACTING THIN SEA ICE AREA FROM SPACE
}

\author{
*Kohei Cho ${ }^{\mathrm{a}}$, Yusuke Mochizuki ${ }^{\mathrm{a}}$, Yuuta Yoshida ${ }^{\mathrm{a}}$, Haruhisa Shimoda and Chi-Farn CHEN ${ }^{\mathrm{b}}$ \\ ${ }^{a}$ Tokai University, 2-28-4 Tomigaya. Shibuya -ku, Tokyo 151-0063 Japan \\ Tel: (81)-3-3481-0611, E-mail: cho@yoyogi.ycc.u-tokai.ac.jp \\ ${ }^{\mathrm{b}}$ Center for Space and Remote Sensing Research (CSRSR) \\ National Central University, E-mail: cfchen@csrsr.ncu.edu.tw
}

\section{Commission VIII, WG VIII/10}

KEY WORDS: Sea of Okhotsk, MODIS, FORMOSAT-2, AMSR-E, optical sensor, passive microwave sensor

\begin{abstract}
:
Global warming is one of the most serious problems the earth is facing in the $21^{\text {st }}$ Century. In order to detect the sign of global warming, the importance of sea ice monitoring is increasing. Especially, sea ice thickness is an key parameter for understanding the heat flux of sea ice area. However, estimation of sea ice thickness with satellite remote sensing is not easy. In this study authors have examined the possibility of extracting thin sea ice area from remotely sensed data from space. The study was performed in the Sea of Okhotsk. Firstly, the possibility of estimating thin ice thickness with high resolution optical sensor RSI(IFOV=8m) on FORMOSAT2 satellite was examined. The comparison of RSI data with in situ measurement of ice thickness suggested the possibility of estimating sea ice thickness with RSI data for less than $20 \mathrm{~cm}$ under the cloudless and snow free condition. The correlation between RSI data and MODIS data(IFOV $=250 \mathrm{~m})$ was also examined for the thin ice area. The result also suggested the possibility of extracting thin sea ice area from MODIS data. Based on these results, the authors have examined possibility of extracting thin sea ice area with passive microwave sensor AMSR-E by using thin ice area estimated with MODIS data as truth data. Since the horizontal polarization of $19 \mathrm{GHz}$ are more sensitive to water than the vertical polarization of $19 \mathrm{GHz}$, the authors have utilized the polarization difference of $19 \mathrm{GHz}$ for extracting thin sea ice area from AMSR-E data. The detailed study result will be presented in this paper.
\end{abstract}

\section{INTRODUCTION}

Sea ice has an important role of reflecting the solar radiation back into space. However, the reduction of ice cover due to the global warming decreases the earth albedo, and increases the amount of solar energy absorption leading to more global warming. This means that the trend of global warming is likely to be enhanced in sea ice area. Sea ice also has a role of preventing heat exchange between sea and air. Especially, since the heat flux of thin ice is strongly affected by the ice thickness difference (Maykut, 1978), ice thickness estimation and thin ice area extraction ice are quite important.

Under the cloud free condition, high resolution optical sensors are quite useful for monitoring the detailed condition of sea ice. Various studies on estimating ice thickness with optical sensor AVHRR onboard NOAA satellites have been performed in the past (some examples are Allison, 1993, Perovich et al., 1982, and Grenfell, 1983). Basically, the albedo increases as the ice thickness increases. However, detailed comparison of thin ice thickness with high resolution satellite data were not much done in the past. In this study, firstly, authors have evaluated the possibility of estimating thin sea ice thickness with high resolution optical sensor RSI data observed from satellite FORMOSAT-2. Then, the RSI data were compared with moderate resolution optical sensor MODIS data acquired from Aqua satellite to evaluate the possibility of extracting thin sea ice area from MODIS images. Finally, the method for extracting thin ice area from passive microwave sensor AMSRE data acquired from Aqua satellite was proposed and the result was evaluated using simultaneously collected MODIS data.

\section{TEST SITE}

In this study, the Sea of Okhotsk was selected as the test site for the detailed evaluation of thin ice area extraction from remotely sensed data from space. Figure 1 show the maps of the test site. The Sea of Okhotsk is located in the north side of Japan, and is one of the most southern seasonal sea ice zones in the northern hemisphere. Since many thin ice area can be found in the Sea of Okhotsk, the sea is suitable for this study. The in situ measurements of ice thickness were performed at the Monbetsu Bay and Saroma Lake along the coast of Hokkaido, Japan.

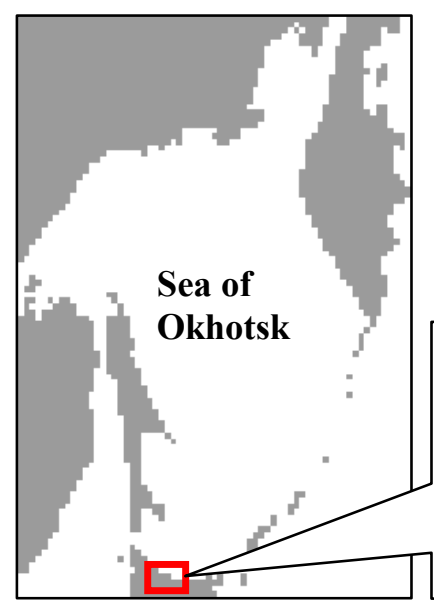

(a) Sea of Okhotsk

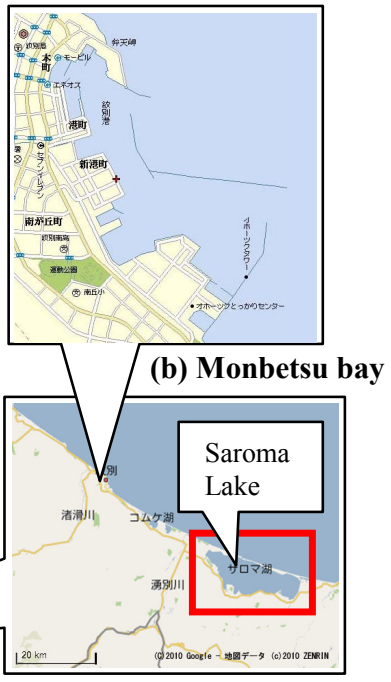

(c) Saroma Lake
Figure 1. Location of test sites 


\section{ANALYZED DATA}

Both optical sensor data and passive microwave sensor data acquired from satellites were analyzed in this study. As for the optical sensor, data from both RSI onboard FOROMSAT-2 satellite and MODIS onboard Aqua satellite were used. As for the passive microwave sensor, data from AMSR-E onboard Aqua satellite were used. Table 1 and 2 show the specifications of the three sensors.

Table 1. Specifications of optical sensors

\begin{tabular}{|c|c|c|c|c|}
\hline Sensor & Band & Wavelength & IFOV & Swath \\
\hline \multirow{4}{*}{ RSI } & PAN & $0.45-0.90 \mu \mathrm{m}$ & $2 \mathrm{~m}$ & \multirow{2}{*}{2} \\
\cline { 2 - 3 } & 1 & $0.45-0.52 \mu \mathrm{m}$ & \multirow{2}{*}{$24 \mathrm{~km}$} \\
\cline { 2 - 3 } & 2 & $0.52-0.60 \mu \mathrm{m}$ & \\
\cline { 2 - 3 } & 3 & $0.63-0.69 \mu \mathrm{m}$ & & \\
\cline { 2 - 3 } & 4 & $0.76-0.90 \mu \mathrm{m}$ & & \\
\hline \multirow{3}{*}{ MODIS } & 1 & $0.620-0.670 \mu \mathrm{m}$ & \multirow{2}{*}{$250 \mathrm{~m}$} & $2330 \mathrm{~km}$ \\
\cline { 2 - 3 } & 2 & $0.841-0.876 \mu \mathrm{m}$ & & \\
\hline
\end{tabular}

Table 2. Specifications of AMSR-E

\begin{tabular}{|c|c|c|c|}
\hline $\begin{array}{c}\text { Frequency } \\
\text { (polarization) }\end{array}$ & IFOV & Swath & $\begin{array}{c}\text { Incident } \\
\text { angle }\end{array}$ \\
\cline { 1 - 2 } $6.925 \mathrm{GHz}(\mathrm{V}, \mathrm{H})$ & $43 \times 75 \mathrm{k} \mathrm{m}$ & & \\
\cline { 1 - 2 } $10.65 \mathrm{GHz}(\mathrm{V}, \mathrm{H})$ & $9 \times 51 \mathrm{k} \mathrm{m}$ & & \\
\cline { 1 - 2 } $18.7 \mathrm{GHz}(\mathrm{V}, \mathrm{H})$ & $16 \times 27 \mathrm{k} \mathrm{m}$ & & \multirow{2}{*}{$55 \mathrm{deg}$} \\
\cline { 1 - 2 } $23.8 \mathrm{GHz}(\mathrm{V}, \mathrm{H})$ & $18 \times 32 \mathrm{k} \mathrm{m}$ & \\
\cline { 1 - 2 } $36.5 \mathrm{GHz}(\mathrm{V}, \mathrm{H})$ & $8.2 \times 14.4 \mathrm{k} \mathrm{m}$ & & \\
\cline { 1 - 2 } $89.0 \mathrm{GHz}(\mathrm{a})$ & $3.7 \times 6.5 \mathrm{k} \mathrm{m}$ & & \\
\cline { 1 - 2 } $89.0 \mathrm{GHz}(\mathrm{b})$ & $3.5 \times 5.9 \mathrm{k} \mathrm{m}$ & & \\
\hline
\end{tabular}

\section{DIRECT MEASUREMENT OF THIN ICE THICKNESS}

In order to evaluate the possibility of estimating thin ice thickness with optical sensors on board satellites, direct measurements of ice thickness were performed in Saroma Lake and Monbetsu Bay. Since the thin ices are very fragile, it is dangerous to stand on the ice. The authors approached to the thin ice on a small boat. The procedure of the ice thickness measurement is shown on Figure 2. The operator makes a small hole in the ice by using a drill (Figure 2(a)). Once the hole is open, the operator inserts a tape measure into the hole (see Figure 2(b)). A bar connected to the forefront of the tape measure act as a prop, and the operator can easily measure the ice thickness with the tape measure (See figure 2(c)). Figure 3 show the Snapshots of the ice thickness measurement in the Saroma Lake.

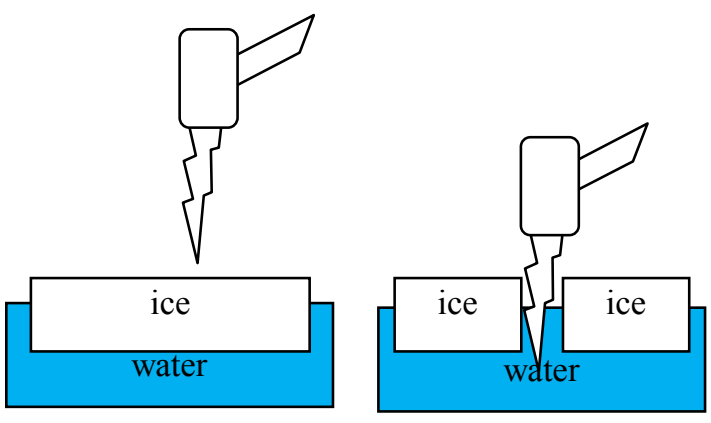

(a)Open a hole in the ice with a drill.

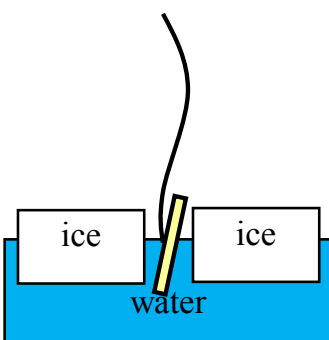

(b) Insert a tape measure into the hole.

Figure 2. Procedure of direct measurement of ice thickness.



(a) Opening a hole on the ice with a drill.

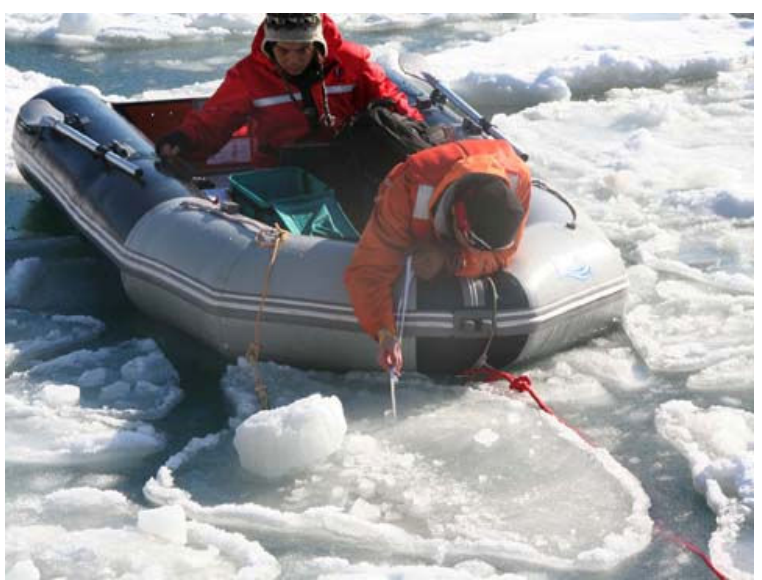

(b) Measuring the ice thickness with a tape measure Figure 3. Direct measurement of ice thickness from a boat. 


\section{COMPARISON OF ICE THICKNESS WITH RSI DATA}

On February 26, 2011, the most part of Saroma Lake were frozen except around the two small mouths of the lake to the Sea of Okhotsk as shown in the FORMOSAT2 RSI image on Figure 6(a). We performed ice thickness measurement from a small boat at the marginal ice area near the first mouth of the lake (See Figure 4(a)). This was quite successful. But, the thickness of ices which we could measure from the boat were around 15 to $20 \mathrm{~cm}$. So, we performed similar experiment on February 25, 2012 at the Monbetsu Bay(See Figure 4(b)). At that time, we could measure many thin sea ices which thicknesses less than $15 \mathrm{~cm}$. The ice thickness of each point were measured several times and averaged.

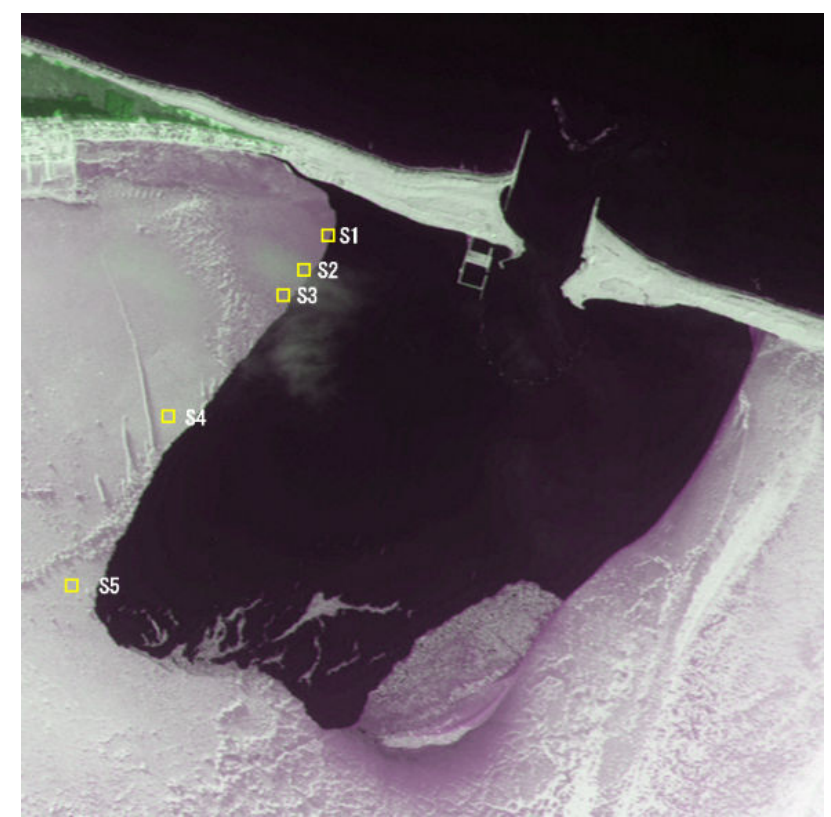

(a) Enterlance of Saroma Lake (Feb. 26, 2011)

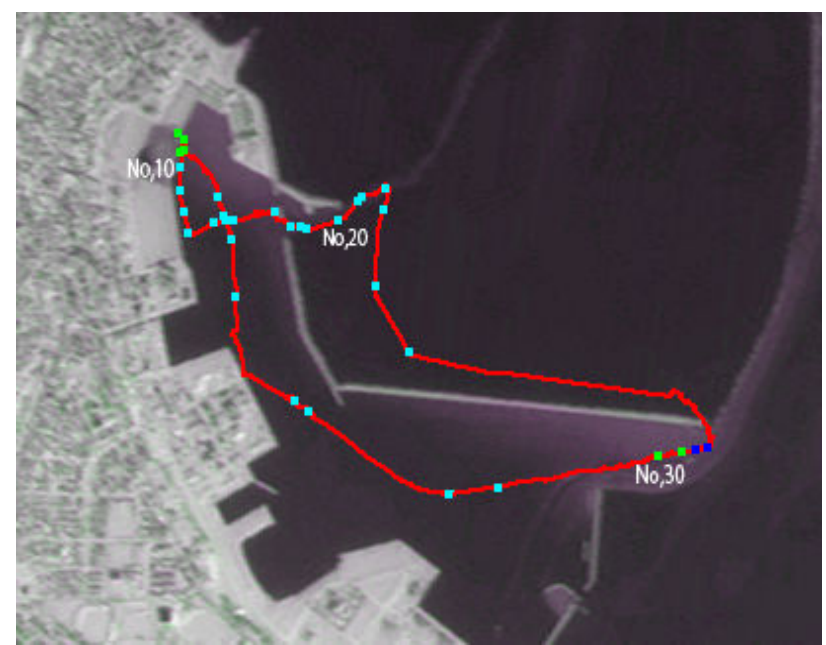

(b) Monbetsu Bay (Feb. 25, 2012)

Figure 4. Measured points plotted on RSI images
Figure 5 shows the relationship between the ice thickness and the radiance derived from RSI band 3 and 4 data measured at the points shown in Figure 4(a) and (b). The linear relationships were observed between the ice thickness and the radiance acquired by RSI for the thin ice area around the mouth of the lake when the ice thicknesses were less than $20 \mathrm{~cm}$. This suggests the possibility of estimating ice thickness of thin ice with high resolution optical sensor such as RSI under the snowless and cloud free condition. Since the data were taken in two different places with one year interval, the result also suggested the stability and reliability of RSI data. As for the ice thicker than $20 \mathrm{~cm}$, our previous study (Cho et. al., 2011) suggested the difficulty of estimating ice thickness with optical sensors.

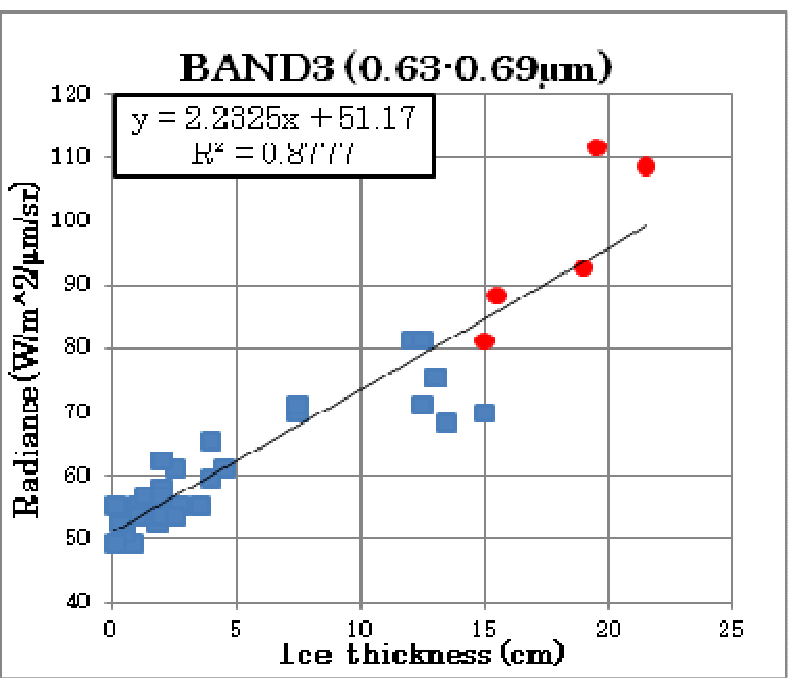

(a) BAND3

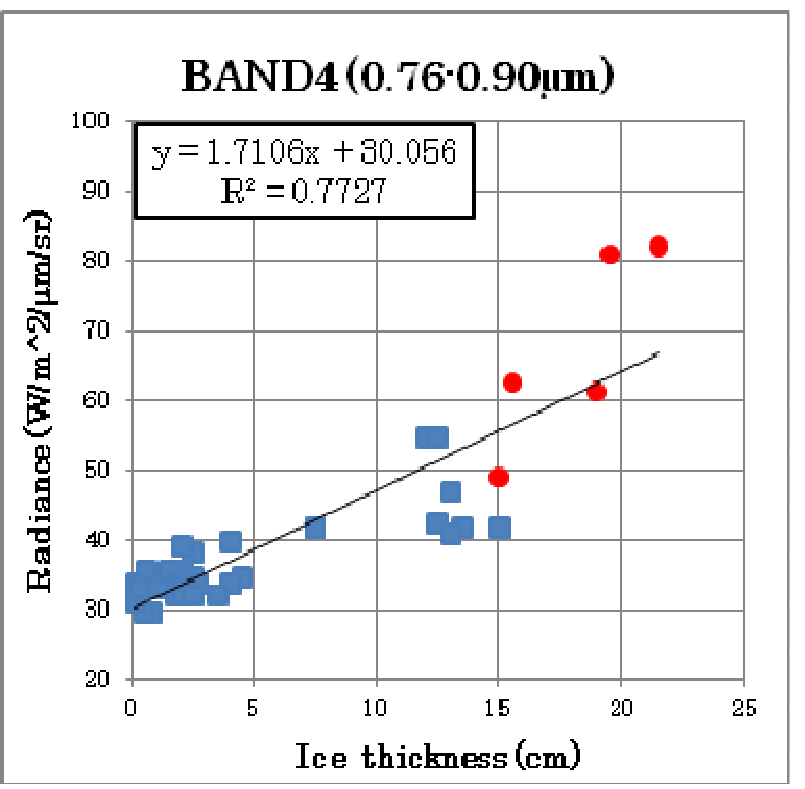

(b) BAND4

Figure 5. Relationship between ice thickness and RSI data 


\section{COMPARISON OF RSI DATA WITH MDOIS DATA}

In this study, authors were considering to use optical sensor data as the "truth data" for evaluating thin ice area extracted with AMSR-E data. Now, we have got good relationship between the ice thickness and RSI data when the ice thicknesses were less than $20 \mathrm{~cm}$. However, since one pixel size of AMSR-E $36.5 \mathrm{GHz}$ band is about the swath of RSI. Direct comparison of RSI data with AMSR-E data is nonsense. So, we decided to compare RSI data with MODIS data. The IFOV size of MODIS is $250 \mathrm{~m}$, which means that one pixel size of AMSR-E $36.5 \mathrm{GHz}$ band is about $100 \times 100$ pixels of MODIS image. This is appropriate size for using MODIS image as "truth data" of AMSR-E (see Figure 8).

On February 19, 2011, RSI and MODIS observed Saroma Lake as shown on Figure 6. The box area in the RSI and MODIS images of the Saroma Lake was compared. Figure 7 shows the scatter plots of RSI band 3 and MODIS band 1 .

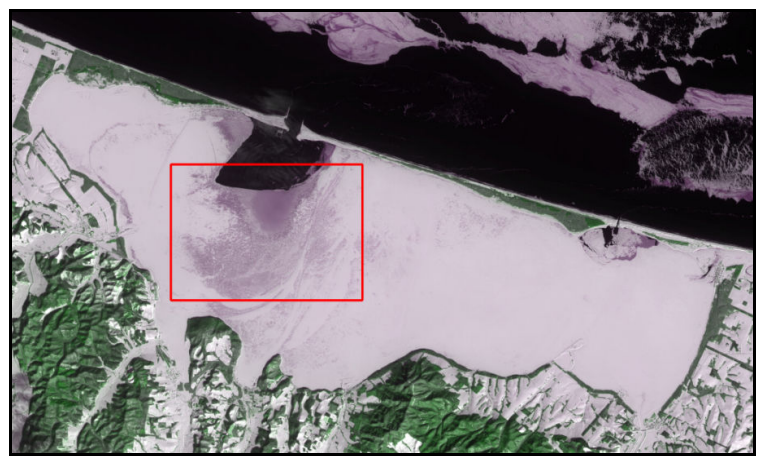

(a) RSI image

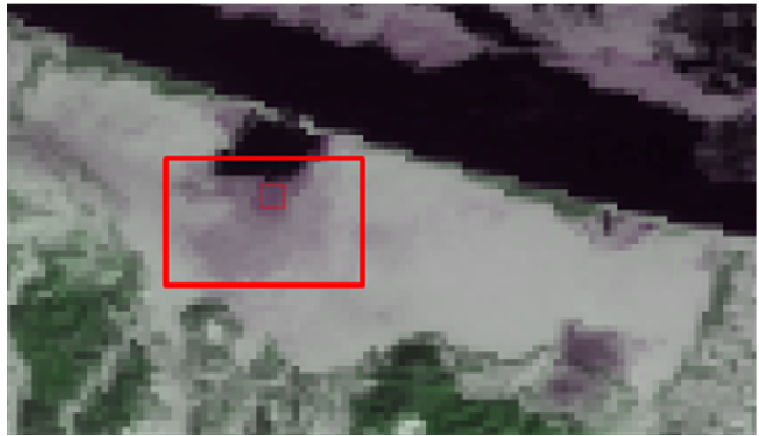

(C) MODIS image

Figure 6. Comparison of RAI image with MODIS image (Saroma Lake, February 19, 2011)



Figure 7. Scatter plots of RSI band 3 versus MODIS band 1 (Saroma Lake, February 19, 2011)

It is clear that both data have very high correlation( $\mathrm{R} 2=0.94)$. This result suggests the possibility of estimating ice thickness with MODIS data under the less snow and cloud free condition. At least, it is fare to say that thin ice area may be estimated using MODIS image.

\section{EXTRACTION OF THIN ICE AREA WITH AMSR-E DATA}

The main purpose of this study was to extract thin sea ice area using passive microwave AMSR-E data. However, considering the difficulty of discriminating thin sea ice from thick sea ice in the low ice concentration areas, we decided to extract only the thin sea ice area with $80 \%$ or higher sea ice concentration. The target will be focused only to seasonal sea ice zones to reject the influence of multi-year ice. Thus, the data will only be calculated before the melting season of the Sea of Okhotsk to reduce the effects of flooding.

Figure 8 show MODIS image and sea ice concentration image derived from AMSR-E data using Bootstrap Algorithm (Comiso, 2009). Since both sensors are on the same Aqua satellite, the data are taken at exactly the same time. In the MODIS images, blue and red are assigned to band 1(visible) and green to band 2(near infrared). In Figure 8(a), dark purple area can be seen along the coast of Russia. As explained in the previous chapters, dark ice area in MODIS image can be estimated as thin ice area. Especially, since the reflectance of ice reduces in band 2 when the ice is covered or surrounded by water, the thin ice areas are likely to appear in purple in the MODIS image.

In order to examine the brightness temperature characteristics of big ice floe, thin ice, mixed ice, and open water, the sample area of each item was selected in the MODIS image as shown on Figure 9. Then the sample areas are overlaid on the AMSR-E image, and the AMSR-E data of the sample areas were extracted.

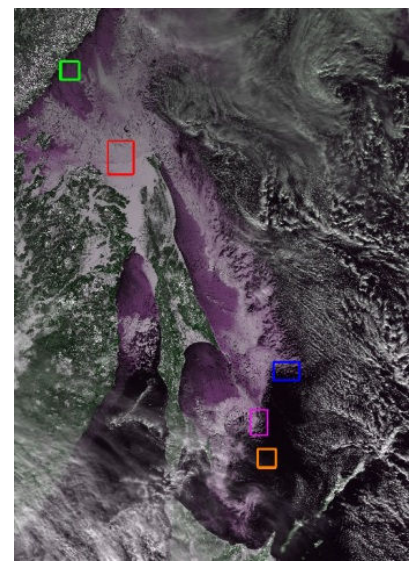

(a) MODIS image (Sea of Okhotsk, Feb. 7, 2009)

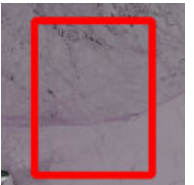

(a)Big ice flo (b) Thin ice

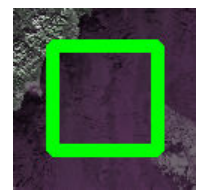

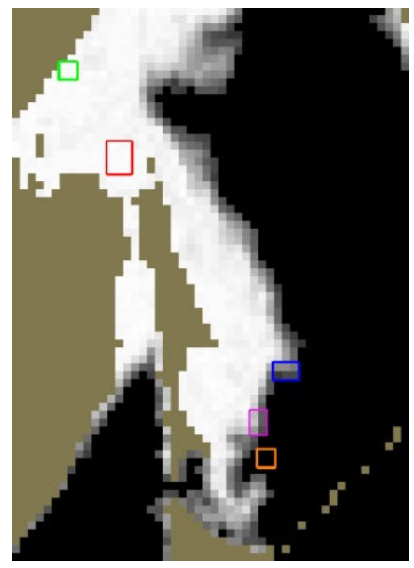

(b) AMSR-E ice concentration
Figure 9. Sample ar MODIS image (Sea of Okhotsk, Feb. 7, 2009) 
Figure 10 shows scatter plots of $19 \mathrm{GHz}$ versus $37 \mathrm{GHz}$ at vertical polarization brightness temperatures of AMSR-E used in Bootstrap Algorithm for the sample areas. This characteristic domain is used for calculating ice concentrations in Bootstrap Algorithm. It is clear that the thin ice area $(\diamond)$ can't be identified with the ice floe(consolidated ice $\square$ ) in this scatter plots. So, the authors have introduced the scatter plots of AMSR-E (19GHz V-19GHz H) versus $37 \mathrm{GHzV}$ as shown on Figure 11. Since thin ice areas are likely to be wet, the polarization difference of $19 \mathrm{GHz}$ brightness temperature in thin ice area increases than big ice floe (consolidated ice). As a result, the thin ice area $(\diamond)$ could be discriminated from big ice floe( $\square)$ in the scatter plots on Figure 11. The authors have introduced following two equations for extracting thin ice area.

$$
\begin{aligned}
& \mathrm{TB}(19 \mathrm{GHzV}-19 \mathrm{GHzH})+\mathrm{TB}(37 \mathrm{GHzV})>300 \mathrm{~K} \\
& \mathrm{~TB}(19 \mathrm{GHzV})>245 \mathrm{~K}
\end{aligned}
$$

The meshed area represents the area extracted with equation (1). Equation (2) is used to reject the sea ice area which concentration is less than approx. 80\%. The red area in Figure 12(a) are the "thin ice areas" extracted with this method. The extracted areas were overlaid on the MODIS image for evaluation as shown on Figure 12(b) and (c). It is clear that most of the thin ice areas which are appearing in dark purple in the MODIS image are successfully extracted with the proposed method. Up to now, we have applyed this method to around ten AMSR-E scenes for the Sea of Okhotsk with success.

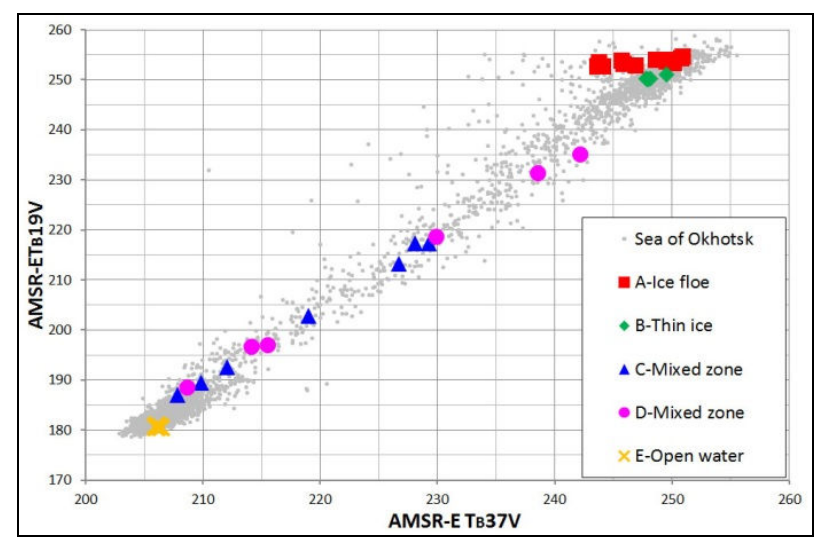

Fig.10 Scatter plots of $19 \mathrm{GHz}$ vs $37 \mathrm{GHz}$ at $\mathrm{V}$ polarization (Sea of Okhotsk, 2009/02/07)

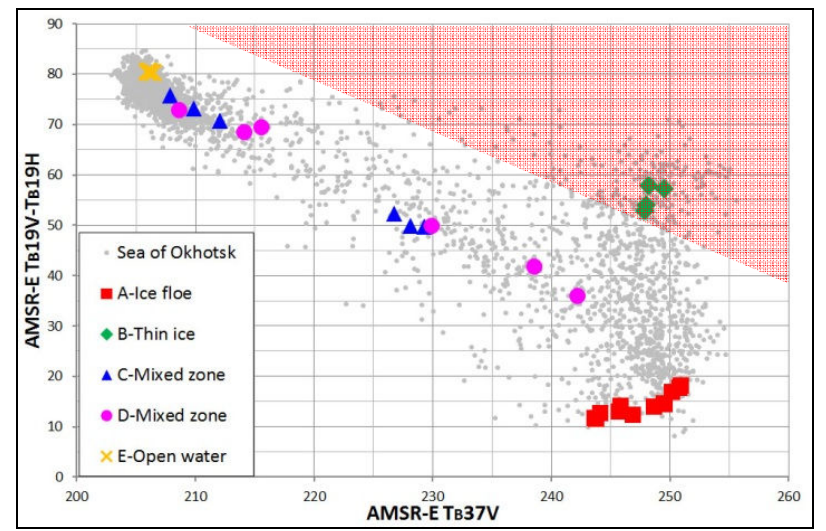

Fig.11 Scatter plots of $T_{B}(19 G H z V-19 G H z H)$ versus $\mathrm{T}_{\mathrm{B}}(37 \mathrm{GHzV})$

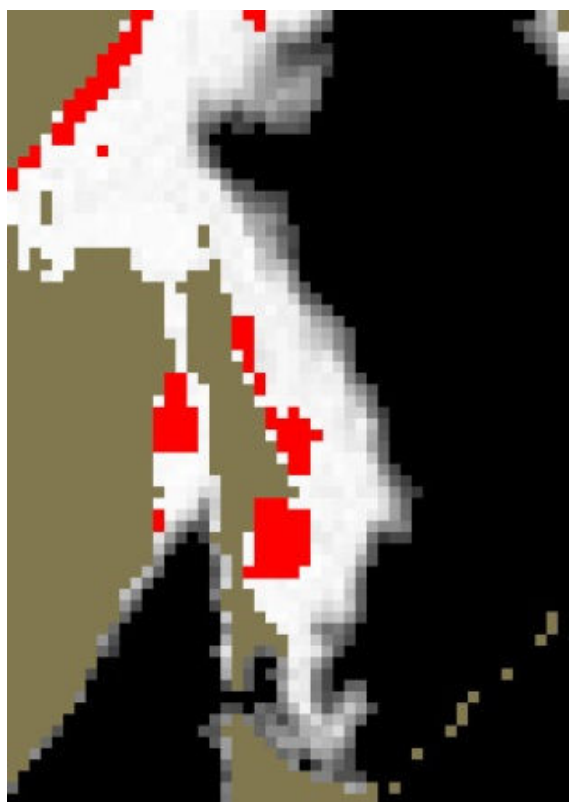

(a)AMSR-E image (Red: extracted area)

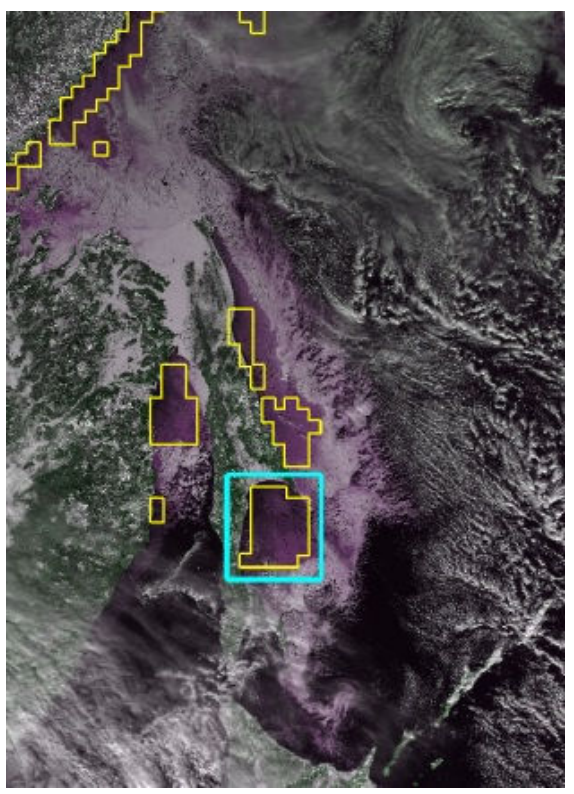

(b)MODIS image

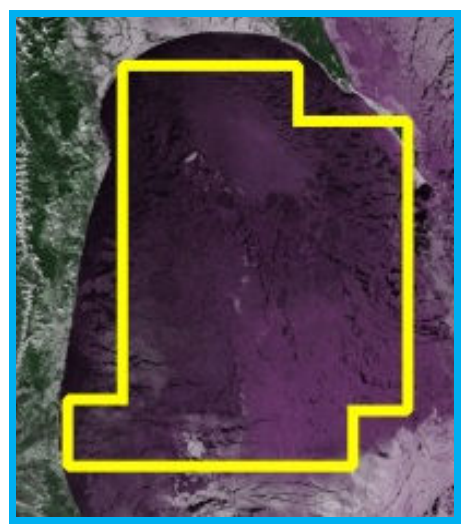

(c) Expansion of the extracted area overlaid on MODIS image

Fig.12 Thin ice area extraction result 


\section{CONCLUSIONS}

In this study the authors have investigated the possibility of estimating thin ice thickness with high resolution optical sensor RSI. The comparison with in situ measurements proved that ice thickness up to $20 \mathrm{~cm}$ could be estimated with visible and near IR band data of RSI under the snow less and cloud free condition. The comparison of RSI data with MODIS data suggested the possibility of estimating thin ice area with MODIS images. Accordingly, MODIS images were used to select sample areas of thin ice. By comparing AMSR-E brightness temperatures characteristics of thin ice area with other sea ice type areas, the authors have introduced the scatter plots of AMSR-E (19GHz V-19GHz H) versus $37 \mathrm{GHzV}$ for extracting thin sea ice area. The extracted thin sea ice areas were validated by comparing with MODIS images. The result proved the effectiveness of this methodology. The authors are now examining the possibility of applying this methodology to the other sea ice zones.

\section{ACKNOWLEDGEMENT}

This study was supported by JAXA under the framework of GCOM-W1 Project. The FORMOSAT-2 data were provided from NSPO. The authors would like to thank JAXA and NSPO for their kind support.

\section{REFERENCES}

1) Maykut, G. A., 1978, Energy exchange over young sea ice in the central arctic, JGR, Vol.83, pp.3646-3658.

Allison, I., "East antarctic sea ice: albedo, thickness distribution, and snow cover", J. Geophys. Res., Vol. 98, pp.12417-12429, 1993.

2) Allison, I., "East antarctic sea ice: albedo, thickness distribution, and snow cover", J. Geophys. Res., Vol. 98, pp.12417-12429, 1993.

3) Perovich, D. K. and T. C. Grenfell, "A theoretical model of radiative transfer in young sea ice", J. Glaciol., Vol.28, pp. 341-356, 1982.

4) Grenfell, T. C., "A theoretical model of the optical properties of sea ice in the visible and near infrared", J. Geophys. Res., 88, 9723-9735, 1983.

5) Comiso, J. C., "Enhanced Sea Ice Concentrations and Ice Extent from AMSR-E Data", Journal of the Remote Sensing Society of Japan, Vol.29, No.1, pp.199-215, 2009.

6) Cho, K., Y. Mochiduki, Y. Yoshida, M. Nakayama, K. Naoki, C.F. CHEN, Thin ice thickness monitoring with FORMOSAT2 RSI data, Proceedings of the 32nd Asian Conference on Remote Sensing, TS1-2, pp.1-8, 2011. 